Манько Т. А. ${ }^{1}$, Гусарова И. А. ${ }^{2}$, Роменская О. П. ${ }^{2}$, Самусенко А. А. ${ }^{2}$

${ }^{1}$ Днепровский национальный университет имени Олеся Гончара. Украина, г. Днепр

${ }^{2}$ Государственное предприятие «Конструкторское бюро "Южное"» им. М. К. Янгеля. Украина, г. Днепр

\title{
ИССЛЕДОВАНИЕ МЕХАНИЧЕСКИХ СВОЙСТВ УГЛЕПЛАСТИКОВ С МОДИФИЦИРОВАННЫМ НАПОЛНИТЕЛЕМ
}

В настолщее время большой интерес вызывает изготовление изделий из полимерных композиционных материалов (ПКМ), поскольку они обладают высокими физико-механическими характеристиками, имеют малый удельный вес и широкий диапазон регулирования свойств в зависимости от предбявляемых к ним требованиям.

Наиболее перспективнымы материаломи для аэрокосмической техники являются ПКМ на основе угольных волокон - углепластики. Свойства углепластиков определяются составом, типом полимерной матрицы, видом и текстурой наполнителя, их взаимодействием на операциях получения полуфабрикатов, формирования и формования материала.

С целью созданияуглепластиков с требуемым уровнем әксплуатационных характеристик в работе предложен метод обработки углеродных волокон. Обработка исходных волокон позволяет повысить әффективность использования свойств исходных материалов в конечном продукте (материале либо конструкции).

В работе рассмотрено влияние плазменной обработки разных типов углеродных волокон на механические свойства углепластиков. Приведен ряд исследований механических свойств углепластиков с модифицированным под воздействием плазменной обработки наполнителем. [dx.doi.org/10.29010/082.4]

Ключевые слова: углепластик; плазма; свойства; микроструктура; испытания. 


\section{Введение}

Углепластики широко применяются в конструкциях ракет космического назначения. Это корпуса ракетных двигателей, элементы сопловых блоков, головные части и т.п. Для их изготовления применяются высокомодульные и высокопрочные углеродные волокна. Существующие технологии формообразования конструкций из углепластиков позволяют реализовать около 45-55\% свойств исходных материалов. Согласно сертификатам качества: предел прочности при растяжении единичных углеродных волокон различных марок 25006000 МПа, а эпоксидных связующих: 70-90 МПа. Теоретическая (расчетная) прочность углепластиков при растяжении составляет $\sigma_{\text {теор }}^{+}=3871 \mathrm{MПа.}$ На практике, определяемая на образцах прочность реальных углепластиков находится на уровне = 1400-2500 МПа, что составляет уже 45-55\% от $\sigma_{\text {теор. }}^{+}$Поэтому большой интерес представляет разработка новых методовобработки исходных материалов с целью реализации их свойств в конструкции (готовом материале).

\section{Объект исследования}

В качестве наполнителя и матрицы для получения углепластика использовали углеродное волокно марки УКН/5000 и трехкомпонентную систему, состоящую из смолы эпоксидной AralditeLY, отвердителя Aradur, ускорителя Accelerator (компания «Huntsman»). Согласно сертификатам качества [1-2]: предел прочности при растяжении единичных угольных волокон марки УКН/5000 составляет 2500-3500 МПа, а трехкомпонентной системы - 80-90 МПа. Разрушающее напряжение при растяжении углепластика составляет около 1100 МПа, а теоретическая прочность 2125 МПа.

Для полной реализации характеристик исходных материалов в углепластиках необходимо обеспечить адгезионную прочность на границе раздела наполнителя с матрицей.

Большой интерес вызывает исследование зависимости свойствуглепластиков от адгезионной прочности соединений на границе «волокно-матрица», а также механизмов обеспечения этой прочности. Необходимым условием достижения прочной адгезионной связи на поверхности раздела в композите является хорошая смачиваемость поверхности наполнителя жидким связующим (адгезивом). Адгезив должен обеспечивать плотный контакт на большой площади поверхности раздела независимо от того какими силами обусловлено возникновение адгезионного соединения: Ван-дерваальсовыми силами или химическими связями [3].

Одним из факторов, влияющих на прочность адгезионной связи между углеродными волокнами и эпоксидной матрицей является наличие активных групп на поверхности углеродных волокон. Эти группы взаимодействуют с функциональными группами эпоксидной матрицы. Чем больше таких групп, тем сильнее связь между углеродными волокнами и эпоксидным связующим. Поверхность углеродного волокна наиболее часто активируют электрохимическим [4], анодным окислением [5], плазменной обработкой [6-8], которые приводят к образованию активных гидроксильных, карбоксильных, фенольных гидроксильных, карбонильных групп.

Целью данной работы является исследование свойств углепластиков с модифицированным наполнителем посредством его обработки плазмой в среде азота и плазмой в среде аллиламина.

Модифицирование волокна производилось по технологии, разработанной компанией VITO (Бельгия). Из модифицированного волокна был изготовлен углепластик методом «мокрой» послойной намотки (15 слоев) на специальную оправку.

\section{Методы исследования механических свойств углепластиков с модифицированным наполнителем}

Исследование влияния плазменной обработки на механические свойствауглепластика с модифицированным наполнителем включают:

- испытанияединичных углеродных волокон на растяжение;

- микроструктурный анализ поверхности единичного волокна;

- испытания микропластиков на растяжение;

- испытания на сдвиг и изгиб углепластика, изготовленного на основе углеродного волокна обработанного плазмой и эпоксидного связующего.

\section{Результаты исследований}

Механические испытания единичных волокон проводили по стандартам [9] и [10] на разрывной машине МРМ-10, оснащенной датчиками усилия, работающими совместно с электронным блоком управления, имеющим выход на ПК. Среднее разрушающее напряжение при растяжении углеродного волокна марки УКН/5000 модифицированного плазмой в среде азота составило 2940 МПа, плазмой в среде аллиламина - 2907 МПа, а исходного той же партии - волокна 2913 МПа. Таким образом, плазменная обработка не оказала существенного не влияния на прочность единичных волокон.

На основе полученных результатов механических испытаний единичных волокон в работе прочность углеволокна при растяжении определяли на основании испытаний «микропластиков» по методике разработанной в ГП «КБ «Южное». 
Микропластик представляет собой отвержденный пропитанный эпоксидным связующим углеродный жгут, в виде пучка волокон в количестве 5000 шт.

Испытания микропластика на растяжение проводили на универсальной испытательной машине Tira Test 2300 по стандарту [11]. Значение прочности в микропластике жгутов, обработанных плазмой в среде азота в микропластике составило 2295 МПа, в среде аллиламина - 2265 МПа, а исходного из той же партии - 2280 МПа. Среднее разрушающее напряжение при растяжении микропластиков из модифицированного углеродного волокна марки УКН/5000 и исходного имеют близкие значения, находящееся в диапазоне разброса значений.

Таким образом предполагается, что плазменная обработка не вызывает деструкцию углеродных волокон. Это подтверждается микроструктурным анализом поверхности углеродного волокна с помощью настольного сканирующего электронного микроскопа Phenom (рис. 1).

Отличительной чертой микроструктуры исходного и обработанных плазмой волокон является то, что на исходном волокне наблюдаются частицы посторонних включений,которые после обработки удалились с поверхности волокна. Микродефекты, микрошероховатости, борозки, которые теоретически бы способствовали механическому сцеплению соприкасающихся фаз, не обнаружены.

Прочность механического сцепления соприкасающихся фаз (волокно-связующее) определяли методом испытания на сдвиг по слою и методом испытаний на изгиб. Испытания проводили по [12] и [13]на универсальной испытательной машине TiraTest 2300 .

Среднее разрушающее напряжение, полученное при испытаниях на изгиб образцов углепластика, изготовленного из модифицированного плазмой в среде азота волокна составило 1261,14 МПа, модифицированного плазмой в среде алллиламина 1264 МПа, из исходного - 935,99 МПа (рис. 2.). Таким образом, увеличение характеристик при сдвиге составляет около 18\% с учетом коэффициента вариации.

Среднее разрушающее напряжение, полученное при испытаниях на сдвиг по слою образцов углепла-
1)

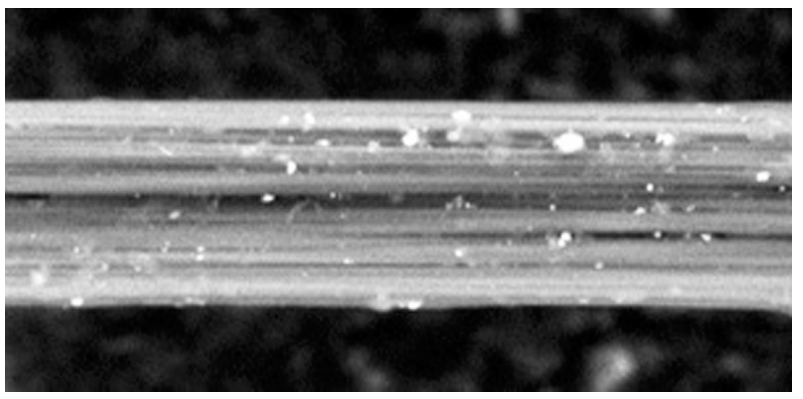

2)
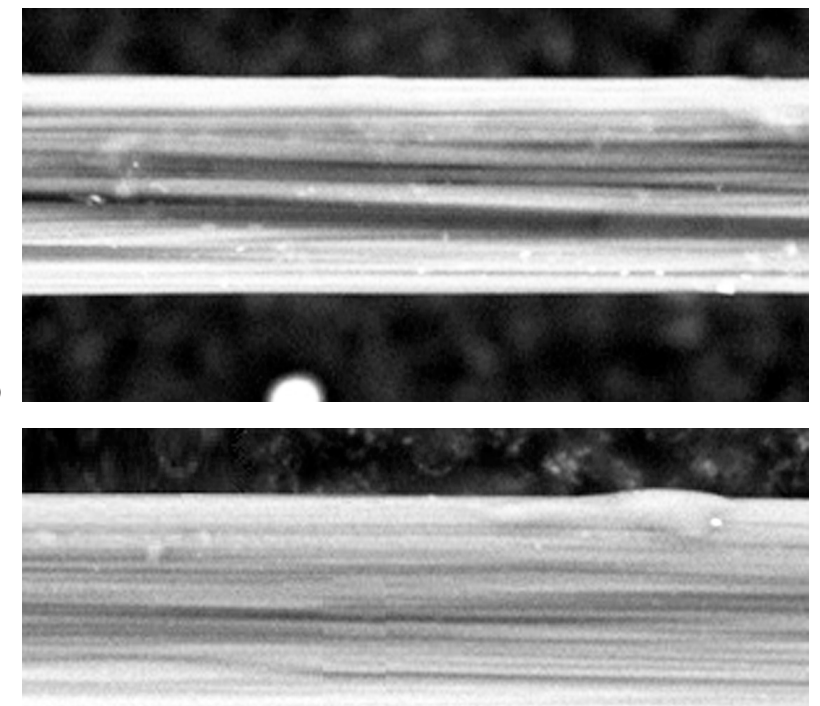

3)

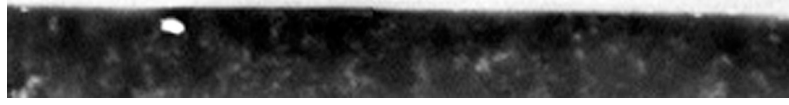

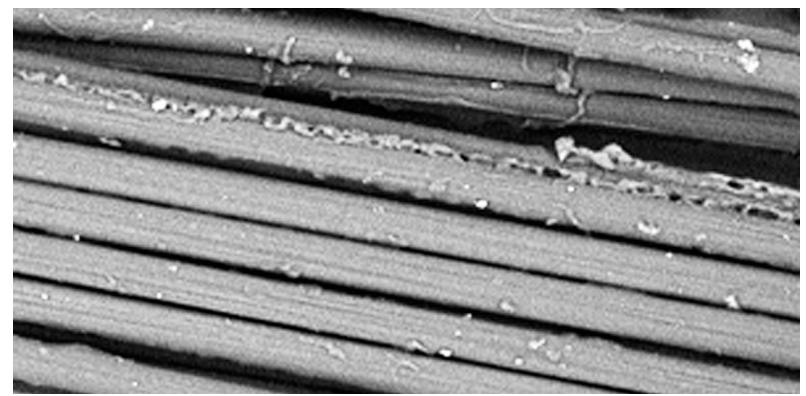
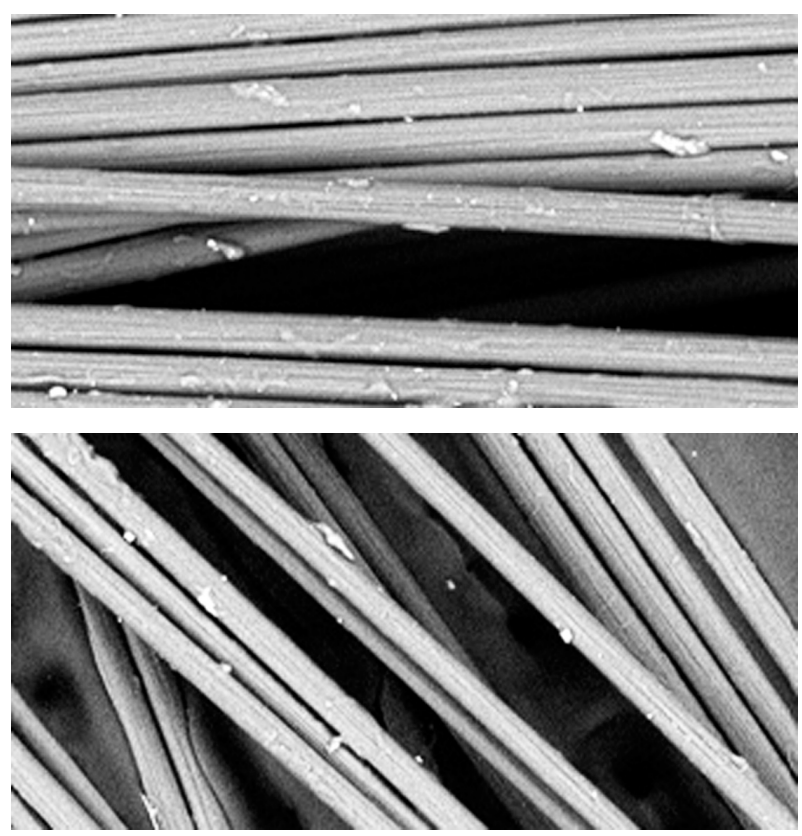

Рис. 1. Микроструктура единичных углеродных волокон (увеличение - 10000× и 2000×):

1) - образцы углеволокон УКН/5000, исходные; 2) - образцы углеволокон полученных обработкой плазмой в среде азота волокна марки УКН $/ 5000 ; 3)$ - образцы углеволокон полученных обработкой плазмой в среде алилламина волокна марки УКН/5000 


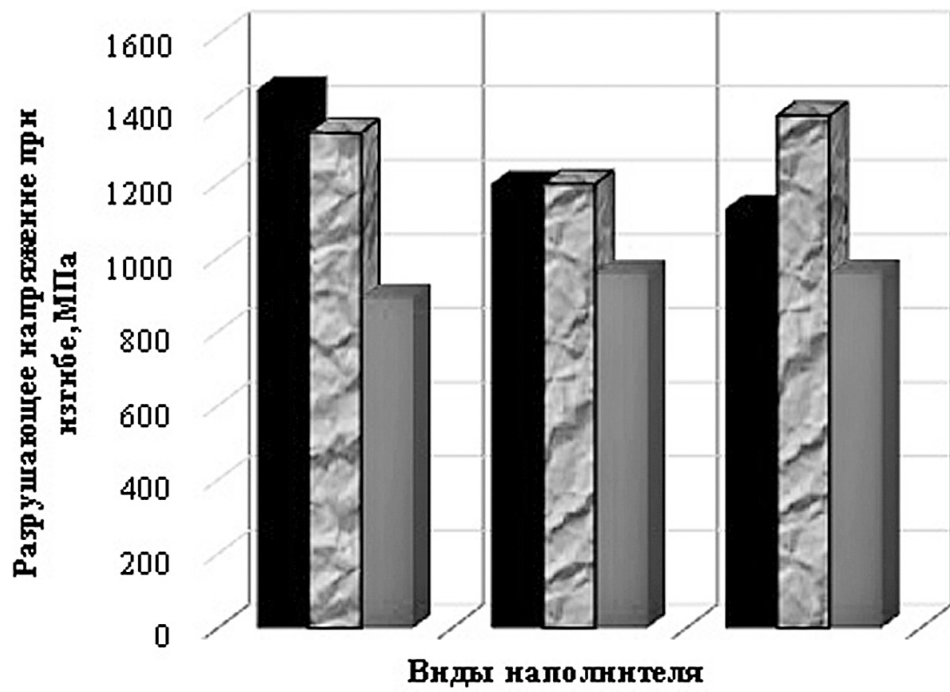

- УKH/5000 (ппазма в среде аллит амгна) + эпоксидное свлзугецее

口 УKH/5000 (ппазма в среде азота) + эпоксидное свлзугощее

口 УKH/S000 (исX одное) + эпоксидное связующе

Рис. 2. Диаграмма зависимости значений разрушающих напряжений при изгибе образцов углепластиков от видов модифицированного плазмой наполнителя.

стика, изготовленного из волокна, модифицированного плазмой в среде азота, составило 46,09 МПа, модифицированного плазмой в среде алллиламина 45,88 МПа, из исходного - 33,37 МПа (рис. 3). Таким образом, увеличение характеристик при изгибе составляет около $15 \%$ с учетом разброса значений.

Полученные результаты подтверждают, что плазменная обработка поверхности углеродных волокон приводит к повышению прочности на границе раздела соприкасающихся фаз (волокно-связующее).

\section{Выводы}

В работе активирование поверхности углеродных волокон проводили путем плазменной обработки с целью увеличения адгезионной прочности, что позволило повысить механические свойства материала.
Приведены результаты испытаний единичных волокон, пропитанных жгутов и углепластиков на их основе.

На основе полученных результатов установлено, что плазменная обработка способствует повышению механических характеристик углепластика по сравнению с исходными (при сдвиге до 18\%, при изгибе $-15 \%)$.

Работы были проведены в рамках Международного контракта ГП «КБ «Южное» с зарубежными партнерами по 7-ой Европейской рамочной программе, проект «NEWSPEC».

\section{Литература}

[1] Паспорт на материалы. Эпоксидное трёхкомпонентное связующее AralditeLY 1135-1 A/Aradur

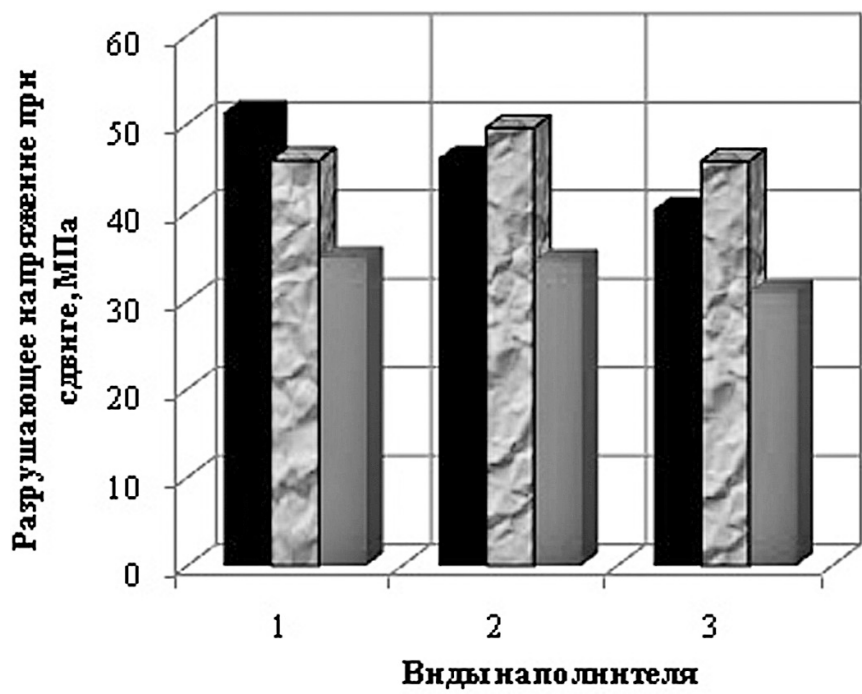

уKH/5000 (плазма в среде азота) + эпоксидное свлзугоще

口УKH/5000 (полама в среде аллип ампна) + эпоксидное св дзугоще

口УKH/5000 (исx одное) + эпоксидное свазугещее

Рис. 3. Диаграмма зависимости значений разрушающих напряжений при сдвиге образцов углепластиков от видов модифицированного плазмой наполнителя 
917 CH/Accelerator 960-1, компании Huntsman (Германия).

[2] Паспорт наугольное волокно марки УКН/5000.

[3] Е.О. Джур, Л.Д. Кучма, Т.А. Манько. Полімерні композиційні матеріали в РКТ, К., Вища школа, 2003, 399 с.

[4] Страхов И.С., Губанов А.А., Устимова М.С., Кривцов Д.И. «Электрохимическая модификация поверхностных свойств углеродного волокна» // Научное издание МГТУ им. Н.Э.Баумана Наука и Образование - 2013. - эл.№ ФС77 - 48211. - c.29-42.

[5] Bismarck A., Kumru M.E., Sprinter J., Simitzis J. Surface properties of PAN-based carbon fiber tuned by anodic oxidation in different alkaline electrolyte system. AppliedSurfaceScience, 1999, vol.143, no.1-4, pp.45-55.

[6] Е.А.Сергеева, А.Р.Ибатуллина, Ф.Ф.Кадыров «Повышение адгезионной способности сверхвысокомолекулярного полиэтиленового волокна с помощью плазменной обработки» // Вестник Казанского технологического университета - 2012. -№4. - c. 123-126.

[7] Е.А.Сергеева, А.Р.Ибатуллина, А.С. Брасаев «Прочностные характеристики композиционных материалов на основе плазмоактивированныхсверхвысоко- молекулярных полиэтиленовых волокон // Вестник Казанского технологического университета 2014. - №7. - c. 133-135.

[8] А.Р.Гарифуллин, И.Ш.Абдуллин, К.Н.Галямова, Е.А.Скидченко «Влияние плазменной обработки на механические свойства пропитанных смолой углеродных волокон при растяжении» // Вестник Казанского технологического университета - 2015. №13. - c. 144-145.

[9] ISO 11566:1996 «Carbon fibre - Determination of the tensile properties of single-filament specimens»

[10] ASTM D 3379-89 «Standard test method for tensile strength and young's modulus for high-modulus singlefilament materials».

[11] ISO 10618 «Carbon fibre - Determination $\mathrm{f}$ tensile properties of resin-impregnated yarn».

[12] ОСТ 92-1462-77 «Пластмассы теплозащитного и конструкционного назначения. Метод испытания на изгиб (по трехточечной схеме)»

[13] ОСТ 92-1472-78 «Пластмассы теплозащитного и конструкционного назначения. Метод испытания на сдвиг по слою».

Manko T. A. ${ }^{1}$, Gysarova I. A. ${ }^{2}$, Romenskaya O. P. ${ }^{2}$, Samusenko A. A. ${ }^{2}$

${ }^{1}$ Oles Gonchar Dnipro National University. Ukraine, Dnipro

${ }^{2}$ Yuzhnoye, State-owned Design Office named after M. K. Yangel. Ukraine, Dnipro

\section{RESEARCH OF MECHANICAL PROPERTIES OF CARBON PLASTICS WITH MODIFIED FILLER}

Manufacture of polymer composite materials (PCM), represents a great interest. This materials have a low specific gravity and a wide range controllable of properties, depending on the operational requirements.

The most promising materials for aerospace engineering are PCM based on carbon fibers - carbon plastics. The properties of carbon plastics are determined by the composition, the type of polymer matrix, the type and texture of the filler, their interaction in the operations of obtaining semi-finished products, forming and molding the material.

In order to create carbon plastics with the required level of performance characteristics, a method for processing carbon fibers is proposed. Processing of raw fibers allows to increase the efficiency of using the properties of the raw materials in the final product (material or construction).

The influence of plasma treatment of different types of carbon fibers on the mechanical properties of carbon plastics is considered. A number of studies of the mechanical properties of carbon plastics with a modified filler modified with plasma treatment are given. [dx.doi.org/10.29010/082.4]

Keywords: carbonplastic; plasma; properties; microstructure; testing.

\section{References}

[1] The Passport on materials. Epoxy binding Araldite LY 1135-1 A/Aradur 917 CH/Accelerator 960-1, companies Huntsman (Germany). 
[2] The Passport on carbon fiber УКН/5000.

[3] E.O. Dzhur, L.D. Kuchma, T.A. Manko. Polymericcompositematerials, K, 2003, 399.

[4] StrakhovI.S., GubanovA.A., UstimovaM.S., KrivtsovD.I. «Elektrokhimicheskaya modifikatsiya poverkhnostnykh svoystv uglerodnogo volokna» // Nauchnoye izdaniye MGTUim. N.E. Baumana Nauka i Obrazovaniye - 2013. - el.№ FS77 - 48211. - p.29-42.

[5] Bismarck A., Kumru M.E., Sprinter J., Simitzis J. Surface properties of PAN-based carbon fiber tuned by anodic oxidation in different alkaline electrolyte system. AppliedSurfaceScience, 1999, vol.143, no.1-4, pp.45-55.

[6] Ye.A.Sergeyeva, A.R.Ibatullina, F.F.Kadyrov «Povysheniye adgezionnoy sposobnosti sverkhvysoko molekulyarnogo polietilenovogo volokna s pomoshch'yu plazmennoy obrabotki» // Vestnik Kazanskogo tekhnologicheskogo universiteta - 2012. -№4. - p. 123-126.

[7] Ye.A.Sergeyeva, A.R.Ibatullina, A.S. Brasayev «Prochnostnyye kharakteristiki kompozitsionnykh materialov na osnove plazmoaktivirovannykh sverkhvysokomolekulyarnykh polietilenovykh volokon // Vestnik Kazanskogo tekhnologicheskogo universiteta - 2014. - №7. - p. 133-135.

[8] A.R.Garifullin, I.SH.Abdullin, K.N.Galyamova, Ye.A.Skidchenko «Vliyaniye plazmennoy obrabotki na mekhanicheskiye svoystva propitannykh smoloy uglerodnykh volokon pri rastyazhenii» // Vestnik Kazanskogo tekhnologicheskogo universiteta - 2015. -№13. - p. 144-145.

[9] ISO 11566:1996 «Carbon fibre - Determination of the tensile properties of single-filament specimens»

[10] ASTM D 3379-89 «Standard test method for tensile strength and young's modulus for high-modulus single-filament materials».

[11] ISO 10618 «Carbon fibre - Determination $\mathrm{f}$ tensile properties of resin-impregnated yarn».

[12] OST 92-1462-76 - Plastic of heat-shielding and constructional appointment. A test method on a bend (under the threedot scheme).

[13] OST 92-1472-78 - Plastic of heat-shielding and constructional appointment. A test method on shift on a layer. 